\title{
Calagem em cultivos sucessivos de cenoura e alface
}

\author{
Paulo E Trani'; Keigo Minami²; Bernardo van Raij; Emílio Sakai'; Simone C Mello²; Sebastião W \\ Tivelli ${ }^{1}$ \\ ${ }^{1}$ Instituto Agronômico, Centro Horticultura, C. Postal 28, 13012-970 Campinas-SP; E-mail: petrani@iac.sp.gov.br; ${ }^{2}$ ESALQ, Dep ${ }^{\text {to }}$. Prod. \\ Vegetal, C. Postal 9, 13418-900 Piracicaba-SP; ${ }^{3}$ Instituto Agronômico, Centro Solos e Rec. Ambientais, C. Postal 28, 13012-970 \\ Campinas-SP; ${ }^{4}$ Instituto Agronômico, Centro Ecofisiologia/Irrig. e Drenagem, C. Postal 28, 13012-970 Campinas-SP
}

\section{RESUMO}

A quantidade de calcário indicada de forma rotineira para hortaliças tem pouca experimentação de campo para dar suporte a níveis de aplicação. Neste trabalho procurou-se estabelecer valores para a saturação por bases $(\mathrm{V})$ e $\mathrm{pH}\left(\mathrm{CaCl}_{2}\right)$ para melhor produtividade e qualidade de cenoura (de inverno) e alface (de verão), cultivadas sucessivamente por três anos agrícolas em um Argissolo Vermelho Amarelo em Monte Alegre do Sul (SP). Avaliou-se a calagem aplicada no ano, bem como o efeito residual da calagem no segundo e terceiro anos subseqüentes. Os tratamentos utilizados foram: $0 ; 2$; $4 ; 6$ e 8 tha $^{-1}$ de calcário no primeiro ano, e 4 e $8 \mathrm{t} \mathrm{ha}^{-1}$ de calcário no segundo e terceiro anos. Constatou-se efeito positivo da calagem sobre a produção e qualidade comercial da cenoura e da alface nos três anos agrícolas e efeito residual da calagem aplicada no primeiro ano do experimento sobre as produções de cenoura e alface nos anos seguintes. No primeiro ano, a produtividade de cenoura comercial foi de $24 \%$ a $39 \%$ maior do que a testemunha sem calcário, enquanto o peso médio da cabeça de alface aumentou de $79 \%$ a $199 \%$. As maiores produtividades de cenoura foram de $46 \mathrm{t} \mathrm{ha}^{-1}$ obtidas com $\mathrm{V}=73 \%$ e $\mathrm{pH}\left(\mathrm{CaCl}_{2}\right)=5,7$. As melhores produções de alface foram atingidas com $\mathrm{V}$ entre $72 \%$ e $80 \%$ e o $\mathrm{pH}\left(\mathrm{CaCl}_{2}\right)$ entre 5,5 e 5,6. A omissão de $\mathrm{B}, \mathrm{Cu}, \mathrm{Mn}$ e $\mathrm{Zn}$ em um dos tratamentos com calagem acarretou na queda de produtividade e qualidade da cenoura nos três anos agrícolas.

Palavras-chave: Daucus carota L., Lactuca sativa L., calcário, rotação de cultura, pH, saturação por bases.

\begin{abstract}
Liming on crop rotation system of carrot and lettuce

Amounts of lime recommended for carrots and lettuce have little experimental support for the amounts indicated. This research was developed to determine the adequate value of soil bases saturation (V) and $\mathrm{pH}\left(\mathrm{CaCl}_{2}\right)$ to obtain the best yield and commercial quality of carrot (winter) and lettuce (summer) cultivated on crop rotation system during three years. The experiment was carried out in Monte Alegre do Sul, São Paulo State, Brazil, on a Typic Kandaudult soil. The residual effect of liming, at the second and third years, was also evaluated. The treatments were: $0 ; 2 ; 4 ; 6$ and $8 \mathrm{tha}^{-1}$ of lime on the first year; 4 and $8 \mathrm{t} \mathrm{ha}^{-1}$ of lime on the second and third years successively. As a result, the positive effects of liming on yield and commercial quality of carrot and lettuce were evident during the three years, and residual effect of liming in the second and third years was evident, too. In the first year, carrot yields were $24 \%$ to $39 \%$ higher than treatment without lime, while lettuce head average weight increased from $79 \%$ to $199 \%$. The highest carrot yields were $46 \mathrm{tha}^{-1}$ obtained at $\mathrm{V}=73 \%$ and $\mathrm{pH}\left(\mathrm{CaCl}_{2}\right)=5,7$. The best commercial results for lettuce were reached with $\mathrm{V}$ between $72 \%$ and $80 \%$ and $\mathrm{pH}\left(\mathrm{CaCl}_{2}\right)$ between 5,5 and 5,6. The treatment with liming and without $\mathrm{B}, \mathrm{Cu}, \mathrm{Mn}$ and $\mathrm{Zn}$ presented lower carrot yield and commercial quality during three years.
\end{abstract}

Keywords: Daucus carota L., Lactuca sativa L., lime, crop rotation, $\mathrm{pH}$, bases saturation.

\section{(Recebido para publicação em 23 de fevereiro de 2005; aceito em 10 de fevereiro de 2006)}

A cenoura e a alface são hortaliças de expressivo consumo no estado de São Paulo, onde em 2003, foram produzidas $105.458 \mathrm{t}$ de cenoura e $57.510 \mathrm{t}$ de alface, cujo valor da produção atingiu $\mathrm{R} \$ 50,8$ milhões e $\mathrm{R} \$ 25,2$ milhões, respectivamente (Tsunechiro et al., 2004).

A acidificação do solo devido à lixiviação de bases trocáveis e a ação de alguns fertilizantes minerais, principalmente amoniacais, tem contribuído para a queda na produtividade e qualidade das culturas, o que pode ser solucionado com o uso de corretivos de solo. A cenoura e a alface são culturas sensíveis à acidez do solo, sendo também consideradas hortaliças exigentes em cálcio e magnésio (Lorenz \& Maynard,
1988; IFA, 1992). No Brasil existe pouca experimentação de campo sobre o efeito da calagem para estas duas hortaliças. O calcário, corretivo da acidez do solo, é também considerado uma fonte eficiente de cálcio e magnésio para as plantas.

Camargo (1960) obteve acréscimos de $29 \%$ e $42 \%$ nas produções de cenoura, em solo cuja calagem atingiu $\mathrm{pH}$ 5,8 e pH 6,5, respectivamente em relação ao $\mathrm{pH} 5,0$, original de um Latossolo Vermelho Amarelo. Segundo Carolus (1975), a cenoura apresentou ganhos de produtividade de $25 \%$ em locais com calagem efetuada para $\mathrm{pH}$ 6,5 em relação a locais com calagem efetuada para pH 5,4. Hemphill \& Jackson (1982) obtiveram maiores produtividades de cenoura com aplicações de calcário que resultaram em valores de $\mathrm{pH}$ de 5,6 e 6,4, em 3 anos agrícolas. Prado et al. (2002), em experimento de vasos, concluíram que uma saturação por bases de $72 \%$ estava associada com $90 \%$ da produção máxima de alface.

Por sua vez, Paterson (1979) ao avaliar a influência do calcário e fertilizantes sobre a produção de cabeças de alface, verificou ser a calagem o fator de maior influência no aumento de produção e no retorno econômico da cultura, quando comparado com os outros tratamentos que constituíram na omissão da aplicação de cada macronutriente $\mathrm{N}, \mathrm{P}$ e K.

Ao contrário das grandes culturas como a soja, milho, algodão, café e citros, são escassas as pesquisas com 
calagem em hortaliças no estado de São Paulo que correlacionem o rendimento das culturas com a saturação por bases do solo. Essa situação motivou a realização deste trabalho, cujo objetivo foi estabelecer relações entre os valores de $\mathrm{V}$ e $\mathrm{pH}\left(\mathrm{CaCl}_{2}\right)$ com as produtividades da cenoura (de inverno) e de alface (de verão), cultivadas em rotação como culturas sucessivas em três anos agrícolas, visando subsidiar a adoção de valores de $\mathrm{V}$ e $\mathrm{pH}$ em $\mathrm{CaCl}_{2}$ a serem adotados na recomendação de calagem. Além disto, foram avaliados os efeitos residuais da calagem no segundo e terceiro anos subseqüentes em relação à aplicação do calcário no primeiro ano. Foi também estudada a aplicação de B, Cu, Mn e Zn na presença e ausência da calagem, considerando que doses crescentes de calcário podem reduzir a disponibilidade destes micronutrientes no solo para a cenoura e alface, entre outras culturas.

\section{MATERIAL E MÉTODOS}

O experimento foi conduzido na Estação Experimental de Monte Alegre do Sul, do Instituto Agronômico do Estado de São Paulo, a 22 $41^{\circ}$ ' de latitude sul e 48 $26^{\prime}$ 'de longitude oeste com uma altitude de $777 \mathrm{~m}$. O clima, segundo classificação de Köppen enquadra-se no subgrupo $\mathrm{Cfa}$, na faixa de clima mesotérmico úmido, sem estiagem.

O solo da área experimental é um Argissolo Vermelho Amarelo distrófico de textura média. Suas características químicas e granulométricas na camada arável $(0-20 \mathrm{~cm})$ são: $\mathrm{pH}$ em $\mathrm{CaCl}_{2}=$ 4,3; M.O. $=18 \mathrm{~g} \mathrm{dm}^{-3} ; \mathrm{P}=7 \mathrm{mg} \mathrm{dm}^{-3} ; \mathrm{K}$ $=1,0 \mathrm{mmol} \cdot \mathrm{dm}^{-3} ; \mathrm{Ca}=12 \mathrm{mmol} \cdot \mathrm{dm}^{-3}$; $\mathrm{Mg}=3,0 \mathrm{mmol} \cdot \mathrm{dm}^{-3} ; \mathrm{H}+\mathrm{Al}=38$ $\mathrm{mmol} \cdot \mathrm{dm}^{-3} ; \mathrm{Cu}=0,6 \mathrm{mg} \mathrm{dm}{ }^{-3} ; \mathrm{Fe}=24,6$ $\mathrm{mg} \mathrm{dm}^{-3} ; \mathrm{Mn}=5,2 \mathrm{mg} \mathrm{dm}^{-3} ; \mathrm{Zn}=1,1$ $\mathrm{mg} \mathrm{dm}{ }^{-3} ; \mathrm{CTC}=54 \mathrm{mmol} \cdot \mathrm{dm}^{-3} ; \mathrm{V}=$ $30 \%$, areia grossa $=200 \mathrm{~g} \mathrm{~kg}^{-1}$; areia fina $=160 \mathrm{~g} \mathrm{~kg}^{-1}$; silte $=320 \mathrm{~g} \mathrm{~kg}^{-1}$ e argila $=$ $320 \mathrm{~g} \mathrm{~kg}^{-1}$.

O experimento foi instalado conforme Gomes \& Conagin (1987), tendo 11 tratamentos, com cinco repetições, dispostos em blocos ao acaso. As diferenças entre as médias dos tratamentos foram comparadas através do teste de Tukey a 5\% de probabilidade. Foi realizada análise de regressão para os resul- tados significativos, determinando-se as equações de regressão.

Dos 11 tratamentos, nove foram constituídos de $0 ; 2 ; 4 ; 6$ e 8 t ha ${ }^{-1}$ de calcário aplicado apenas no primeiro ano; 4 e 8 t ha $^{-1}$ de calcário aplicado apenas no segundo ano; 4 e $8 \mathrm{t} \mathrm{ha}^{-1}$ de calcário aplicado apenas no terceiro ano. Para o solo deste experimento, a recomendação de calagem para atingir um valor de $\mathrm{V}$ de $80 \%$, atual recomendação para cenoura e alface (Trani \& Raij, 1997), seria da ordem de $3 \mathrm{t} \mathrm{ha}^{-1}$. Contudo, como já é fato constatado que os valores atingidos de saturação por bases, em geral, são bem menores do que as metas de calagem (Raij \& Quaggio, 1997), optou-se por recomendações mais elevadas, visando obter curvas de resposta completas.

A aplicação de calcário de 0 a $20 \mathrm{~cm}$ de profundidade, nesses tratamentos, nos respectivos anos, foi realizada aos 30 dias antes da semeadura da cenoura de inverno, estudando-se também o efeito desta calagem, na alface de verão.

Dos dois tratamentos restantes, um consistiu na ausência de calagem e de Ca, substituindo o superfosfato simples (20\% Ca) pelo fosfato monoamônico (MAP com $0 \% \mathrm{Ca}$ ), visando separar o efeito do calcário como corretivo do $\mathrm{pH}$ do solo do seu efeito fornecedor de cálcio às plantas. Um último tratamento consistiu na ausência dos micronutrientes boro, cobre, manganês e zinco com a dose fixa de $4 \mathrm{t} \mathrm{ha}^{-1}$ de calcário no primeiro ano. Em todos os demais tratamentos estes micronutrientes foram aplicados, nas seguintes doses: $10 \mathrm{~kg} \mathrm{ha}^{-1} \mathrm{de}$ sulfato de zinco $(21 \% \mathrm{Zn}), 15 \mathrm{~kg} \mathrm{ha}^{-1} \mathrm{de}$ bórax $(11 \% \mathrm{~B}), 5 \mathrm{~kg} \mathrm{ha}^{-1}$ de sulfato de cobre $(35 \% \mathrm{Cu})$ e $5 \mathrm{~kg} \mathrm{ha}^{-1}$ de sulfato de manganês (25\% Mn).

Utilizou-se de calcário com $30 \%$ de $\mathrm{CaO}$ e $18 \%$ de $\mathrm{MgO}, 98 \%$ de poder de neutralização (PN) e 96\% de poder relativo de neutralização total (PRNT). Este corretivo de acidez é denominado calcário fino, ou "filler", o qual propicia a correção do $\mathrm{pH}$ do solo cerca de 30 dias após sua incorporação.

As parcelas foram representadas por canteiros de $3 \mathrm{~m}$ de comprimento por 1 $\mathrm{m}$ de largura. A cenoura cultivar Nantes foi semeada no espaçamento de $0,20 \mathrm{~m}$ nas entrelinhas constituindo-se como área útil as três linhas centrais do canteiro, totalizando $1,728 \mathrm{~m}^{2}$. A alface cultivar Brasil 221 foi semeada no espaçamento de $0,25 \times 0,25 \mathrm{~m}$ sendo considerada como área útil as duas linhas centrais do canteiro, totalizando uma área útil de $1,25 \mathrm{~m}^{2}$. Para efeito do cálculo de produtividade, considerou-se que um hectare representa $7.000 \mathrm{~m}^{2}$ de canteiros.

Visando a melhoria das condições físicas do solo e considerando que a maioria dos olericultores paulistas adota a adubação orgânica em pré-plantio, em todos tratamentos foram aplicados nos três anos agrícolas $1 \mathrm{~kg}$ de esterco de galinha curtido por metro quadrado aos 30 dias antes da semeadura da cenoura. $\mathrm{O}$ esterco de galinha, analisado conforme metodologia descrita em Brasil (1983), apresentou a composição: N $=9,8 ; \mathrm{P}_{2} \mathrm{O}_{5}($ total $)=30,3 ; \mathrm{K}_{2} \mathrm{O}$ (total $)=$ 4,6; $\mathrm{Ca}=35,4 ; \mathrm{Mg}=3,6 ; \mathrm{S}=1,4\left(\mathrm{~g} \mathrm{~kg}^{-1}\right.$ da matéria seca); umidade $\left(\right.$ a $\left.65^{\circ} \mathrm{C}\right)=$ $40 \% ; \mathrm{pH}=8,6$ e relação $\mathrm{C} / \mathrm{N}=10 / 1$. Os micronutrientes presentes neste esterco foram: $\mathrm{B}=63 ; \mathrm{Cu}=111 ; \mathrm{Fe}=7029$; $\mathrm{Mn}=539 ; \mathrm{Zn}=339\left(\mathrm{mg} \mathrm{kg}^{-1}\right.$ da matéria seca).

As adubações minerais de plantio e cobertura, para a cenoura e a alface, foram realizadas conforme análise de solo do local, seguindo recomendações de Trani \& Raij (1997). Utilizaram-se os fertilizantes sulfato de amônio, superfosfatos simples e triplo, e cloreto de potássio como fontes de $\mathrm{N}, \mathrm{P}_{2} \mathrm{O}_{5} \mathrm{e}$ $\mathrm{K}_{2} \mathrm{O}$, respectivamente. No tratamento em que não se aplicou o cálcio na forma mineral substituíram-se os superfosfatos pelo fosfato monoamônico ( $\mathrm{MAP}=0 \% \mathrm{Ca}$ ).

As produtividades da cenoura comercial e total foram avaliadas quanto ao peso das raízes nos três anos do experimento. As produções de alface foram avaliadas nos três anos do experimento quanto ao peso (gramas) e o maior diâmetro das cabeças da alface $(\mathrm{cm})$.

\section{RESULTADOS E DISCUSSÃO}

A aplicação de calcário no próprio ano proporcionou maior produção total de cenoura, em relação à testemunha, nos três anos agrícolas, o mesmo se verificando para a produção de cenoura 
comercial (Tabela 1). No primeiro ano, a produtividade de cenoura foi de $24 \%$ a $39 \%$ maior do que a testemunha sem calcário. Além disso, observou-se efeito residual de $8 \mathrm{t} \mathrm{ha}^{-1}$ de calcário aplicado em anos anteriores similar ao efeito de $4 \mathrm{t} \mathrm{ha}^{-1}$ de calcário aplicado no ano sobre as produções de cenoura comercial e total, concordando com Laughlin et al. (1987).

O aumento da produtividade de cenoura resultante da calagem também foi constatado por Camargo (1960), que constatou resposta tanto no ano da aplicação como para o efeito residual do calcário aplicado. As melhores doses de calcário encontradas pelo autor se situaram entre 2,5 e 5 t ha $^{-1}$, inferiores às deste trabalho. As diferenças provavelmente se devem à variação na classe de solo, condições climáticas e tipo de calcário utilizado.

Hemphill \& Jackson (1982) e Laughlin et al. (1987) obtiveram maiores produtividades de cenoura em função da calagem. Laughlin et al. (1987) observaram aumento na produtividade de cenoura em dois dos três anos estudados, sugerindo-se haver efeito das variações climáticas. Isso explica em parte os resultados desse trabalho, onde nos três anos do experimento, verificaram-se diferentes produções de cenoura para as mesmas quantidades de calcário utilizadas.

O uso do MAP (sem cálcio) reduziu a produtividade em relação à testemunha (sem calagem) no segundo e terceiro ano do experimento, porém sem diferir estatisticamente, à exceção da produtividade comercial no ano 3 que foi significativamente menor do que a testemunha sem calcário (Tabela 1). Esse resultado evidencia a importância do cálcio para as hortaliças em questão.

$\mathrm{O}$ tratamento sem micronutrientes, com aplicação de $4 \mathrm{t} \mathrm{ha}^{-1}$ de calcário no primeiro ano, reduziu as produtividades de cenoura total e comercial nos três anos agrícolas em relação ao tratamento com $4 \mathrm{t} \mathrm{ha}^{-1}$ de calcário aplicado no primeiro ano, mais os micronutrientes B, Cu, Mn e Zn (Tabela 1).

A produtividade máxima de cenoura no primeiro ano foi de $46,1 \mathrm{t} \mathrm{ha}^{-1}$ para uma saturação por bases de $73 \%$, conforme Figura 1a. No segundo e terceiro

Tabela 1. Produtividade total e comercial de cenoura em toneladas por hectare em função da calagem efetuada em cada ano do experimento realizado em Monte Alegre do Sul. Campinas, IAC, 1989 a 1992.

\begin{tabular}{|c|c|c|c|c|c|c|}
\hline \multirow{3}{*}{ Doses de Calcário } & \multicolumn{6}{|c|}{ Produtividade (t ha-1) } \\
\hline & Total & Comerc. & Total & Comerc. & Total & Comerc. \\
\hline & \multicolumn{2}{|c|}{ ano 1} & \multicolumn{2}{|c|}{ ano 2} & \multicolumn{2}{|c|}{ ano 3} \\
\hline sem calcário & $35,2 \mathrm{c}$ & $28,8 \mathrm{~b}$ & $25,0 \mathrm{~cd}$ & $17,0 \mathrm{de}$ & $27,8 \mathrm{~cd}$ & $19,7 \mathrm{de}$ \\
\hline $2 \mathrm{t} \mathrm{ha}^{-1}$ (ano 1) & $42,0 a b$ & 35,6 a & $26,0 \mathrm{bcd}$ & $18,5 \mathrm{~cd}$ & $28,0 \mathrm{~cd}$ & $20,1 \mathrm{de}$ \\
\hline 4 t ha $^{-1}$ (ano 1) & $46,4 \mathrm{a}$ & $39,2 \mathrm{a}$ & $27,0 \mathrm{bc}$ & $20,9 \mathrm{bc}$ & $31,9 \mathrm{bc}$ & $23,8 \mathrm{~cd}$ \\
\hline $6 \mathrm{t} \mathrm{ha}^{-1}$ (ano 1 ) & $45,5 \mathrm{a}$ & $40,1 \mathrm{a}$ & $29,6 a b$ & $23,8 a b$ & $32,3 \mathrm{bc}$ & $23,9 \mathrm{~cd}$ \\
\hline 8 t ha $^{-1}$ (ano 1) & 45,3 a & $38,0 \mathrm{a}$ & 32,5 a & 26,3 a & $33,9 a b c$ & $27,1 \mathrm{bc}$ \\
\hline 4 t ha $^{-1}$ (ano 2) & $36,9 \mathrm{bc}$ & $29,4 b$ & 33,0 a & $27,1 \mathrm{a}$ & $33,0 \mathrm{abc}$ & $26,1 \mathrm{bc}$ \\
\hline 8 t ha $^{-1}$ (ano 2) & $35,4 \mathrm{c}$ & $29,4 b$ & 33,0 a & 27,0 a & $37,3 a b$ & $31,5 a b$ \\
\hline 4 t ha $^{-1}$ (ano 3 ) & $34,3 \mathrm{c}$ & $27,7 b$ & $26,0 \mathrm{bcd}$ & $17,6 \mathrm{~cd}$ & $37,7 a b$ & $31,7 a b$ \\
\hline $8 \mathrm{t} \mathrm{ha}^{-1}$ (ano 3 ) & $34,5 \mathrm{c}$ & $28,1 \mathrm{~b}$ & $24,8 \mathrm{bcd}$ & $17,4 \mathrm{~cd}$ & $39,1 \mathrm{a}$ & $33,1 \mathrm{a}$ \\
\hline MAP (sem cálcio) & $36,7 \mathrm{bc}$ & $26,3 \mathrm{~b}$ & $22,6 \mathrm{~d}$ & $12,2 \mathrm{f}$ & $22,5 \mathrm{~d}$ & $11,7 \mathrm{f}$ \\
\hline Sem micro $+4 \mathrm{t} \mathrm{ha}^{-1}$ & $36,6 \mathrm{bc}$ & $24,9 \mathrm{~b}$ & $22,8 \mathrm{~d}$ & 13,6 ef & $23,8 \mathrm{~d}$ & 14,9 ef \\
\hline D.M.S. 5\% (Tukey) & 6,1 & 5,1 & 4,2 & 3,6 & 6,1 & 5,6 \\
\hline C.V. $(\%)$ & 7,3 & 7,5 & 7,0 & 8,4 & 9,0 & 10,8 \\
\hline
\end{tabular}

Médias seguidas da mesma letra não diferem significativamente entre si, pelo teste de Tukey a $5 \%$ de probabilidade.

anos, as doses de calcário proporcionaram uma relação linear entre a produtividade e V. Nestes anos não foram estimadas as produtividades máximas em função da V. Houve efeito do calcário aplicado nos três anos agrícolas sobre o $\mathrm{pH}\left(\mathrm{CaCl}_{2}\right)$ do solo e as produtividades máximas de cenoura obtidas. As maiores produtividades de cenoura foram 46,3 $\mathrm{t} \mathrm{ha}^{-1}$ para o $\mathrm{pH} 5,7$ e 33,8 $\mathrm{t} \mathrm{ha}^{-1}$ para o $\mathrm{pH} \mathrm{5,0} \mathrm{no} \mathrm{primeiro} \mathrm{e} \mathrm{segundo}$ anos do experimento, respectivamente (Figura 1b). As diferenças de produtividade entre os anos para as mesmas doses de calcário podem ter sido causadas por fatores climáticos, de forma similar à constatação de Hemphill \& Jackson (1982) e a acidificação do solo pelos fertilizantes aplicados no primeiro ano. No terceiro ano, verificou-se relação linear e positiva entre o pH do solo e a produtividade de cenoura.

Como a atual recomendação de calagem dessas duas culturas é para uma meta de $80 \%$ de saturação por bases (Trani \& Raij, 1997) e as melhores produtividades de cenoura e alface foram obtidas decorrentes de doses muito acima do que seria recomendado, fica constatada a necessidade de maior número de experimentos de calagem em diversos tipos de solo para o aperfeiçoamento das tabelas de recomendação de calagem para cenoura e alface.
No período de 1998 a 2003, o menor preço alcançado pela caixa de $25 \mathrm{~kg}$ de cenoura no Entreposto Terminal de São Paulo (ETSP) da Companhia de Entrepostos e Armazéns Gerais de São Paulo (CEAGESP) foi de R\$ 9,20 (Camargo Filho et al., 2005), enquanto o preço da tonelada de calcário foi de $\mathrm{R} \$ 45,00$, na região de Campinas. Portanto, sem considerar o efeito residual do calcário no segundo e terceiro anos desse experimento, a taxa de retorno ao investimento em calcário, para a melhor produtividade comercial de cenoura no primeiro ano $\left(40,1 \mathrm{t} \mathrm{ha}^{-1}\right)$ foi de $1440 \%$, ou seja, para cada $\mathrm{R} \$ 1,00$ investido em calcário, o produtor obteve $\mathrm{R} \$ 15,40 \mathrm{em}$ retorno.

A aplicação de calcário afetou as produções de alface e o diâmetro da cabeça (qualidade comercial), nos três anos agrícolas (Tabela 2). No primeiro ano de aplicação do calcário, o peso médio e o diâmetro da cabeça de alface foram significativamente maiores do que testemunha sem calcário, com exceção para o diâmetro da cabeça obtido com a dose de $2 \mathrm{t} \mathrm{ha}^{-1}$ de calcário. No primeiro ano, o peso médio da cabeça de alface foi de $79 \%$ a $199 \%$ maior do que a testemunha sem calcário. A dose de $8 \mathrm{t} \mathrm{ha}^{-1}$ de calcário aplicado no primeiro ano proporcionou um aumento no peso médio da cabeça de alface de 
Tabela 2. Peso médio e diâmetro da cabeça de alface em função da calagem efetuada em cada ano do experimento realizado em Monte Alegre do Sul, SP. Campinas, IAC, 1989 a 1992.

\begin{tabular}{|c|c|c|c|c|c|c|}
\hline \multirow[t]{2}{*}{ Doses de calcário } & $\begin{array}{l}\text { Peso } \\
\text { (g) }\end{array}$ & $\begin{array}{c}\text { Diâmetro } \\
(\mathbf{c m})\end{array}$ & $\begin{array}{c}\text { Peso } \\
\text { (g) }\end{array}$ & $\begin{array}{c}\text { Diâmetro } \\
(\mathbf{c m})\end{array}$ & $\begin{array}{l}\text { Peso } \\
\text { (g) }\end{array}$ & $\begin{array}{c}\text { Diâmetro } \\
(\mathbf{c m})\end{array}$ \\
\hline & \multicolumn{2}{|c|}{ ano 1} & \multicolumn{2}{|c|}{ ano 2} & \multicolumn{2}{|c|}{ ano 3} \\
\hline sem calcário & $38,2 \mathrm{e}$ & 14,2 ef & $47,0 \mathrm{~d}$ & $13,8 \mathrm{~d}$ & 51,0 ef & $13,2 \mathrm{e}$ \\
\hline $2 \mathrm{t} \mathrm{ha}^{-1}$ (ano 1) & $68,2 \mathrm{~cd}$ & 17,6 abcde & $61,4 \mathrm{~cd}$ & $16,6 \mathrm{~cd}$ & 59,2 def & 14,6 de \\
\hline $4 \mathrm{t} \mathrm{ha}^{-1}$ (ano 1) & $92,2 a b$ & $19,4 a b$ & $86,8 \mathrm{bc}$ & $19,6 \mathrm{bc}$ & 77,6 cde & $16,8 \mathrm{~cd}$ \\
\hline $6 \mathrm{t} \mathrm{ha}^{-1}$ (ano 1) & $107,0 \mathrm{a}$ & $19,2 a b$ & $98,2 \mathrm{~b}$ & $21,0 a b$ & $104,2 \mathrm{bc}$ & $18,4 \mathrm{bc}$ \\
\hline $8 \mathrm{t} \mathrm{ha}^{-1}$ (ano 1) & $114,2 \mathrm{a}$ & 20,8 a & $110,2 \mathrm{~b}$ & $22,6 a b$ & $118,6 \mathrm{bc}$ & $19,6 \mathrm{bc}$ \\
\hline $4 \mathrm{t} \mathrm{ha}^{-1}$ (ano 2 ) & $43,0 \mathrm{e}$ & $15,6 \mathrm{cdef}$ & $111,4 b$ & $22,6 a b$ & $97,6 \mathrm{bcd}$ & $18,2 \mathrm{bc}$ \\
\hline $8 \mathrm{t} \mathrm{ha}^{-1}$ (ano 2) & $45,6 \mathrm{de}$ & 16,0 bcdef & 148,6 a & $24,0 \mathrm{a}$ & $134,6 \mathrm{ab}$ & $21,2 a b$ \\
\hline $4 \mathrm{t} \mathrm{ha}^{-1}$ (ano 3 ) & $42,2 \mathrm{e}$ & 14,8 def & $41,4 \mathrm{de}$ & $14,8 \mathrm{~d}$ & $116,4 \mathrm{bc}$ & $20,8 a b$ \\
\hline 8 t ha $^{-1}$ (ano 3) & $38,2 \mathrm{e}$ & $15,0 \mathrm{cdef}$ & $37,6 \mathrm{de}$ & $14,0 \mathrm{~d}$ & $176,4 \mathrm{a}$ & 23,8 a \\
\hline MAP (sem cálcio) & $33,6 \mathrm{e}$ & $13,0 \mathrm{f}$ & $13,0 \mathrm{e}$ & 9,6 e & $18,0 \mathrm{f}$ & $9,6 \mathrm{f}$ \\
\hline Sem micro $+4 \mathrm{t} \mathrm{ha}^{-1}$ & $82,2 \mathrm{bc}$ & $18,2 \mathrm{abcd}$ & $81,4 \mathrm{bc}$ & $19,0 \mathrm{bc}$ & $96,8 \mathrm{bcd}$ & $18,4 \mathrm{bc}$ \\
\hline D.M.S. 5\% (Tukey) & 23,5 & 3,5 & 30,0 & 4,2 & 42,1 & 3,2 \\
\hline C.V. $(\%)$ & 16,2 & 9,5 & 18,3 & 10,8 & 20,5 & 8,5 \\
\hline
\end{tabular}

Médias seguidas da mesma letra não diferem significativamente entre si, pelo teste de Tukey a $5 \%$ de probabilidade.

$199 \%, 134 \%$ e $133 \%$ em relação à testemunha sem calcário, respectivamente para os anos 1,2 e 3 .

O peso médio da cabeça de alface obtida com a aplicação de $8 \mathrm{t} \mathrm{ha}^{-1}$ de calcário no ano $3(176,4 \mathrm{~g})$ mostrou-se superior ao peso da cabeça decorrente do efeito residual de $8 \mathrm{t} \mathrm{ha}^{-1}$ de calcário aplicado no ano 1 do experimento, ou seja 118,6 g constatando-se o mesmo para os diâmetros das cabeças de alface. Quanto ao efeito residual do calcário, observou-se que a dose de $8 \mathrm{t} \mathrm{ha}^{-1}$ de calcário, aplicado em anos anteriores, foi semelhante ao efeito de $4 \mathrm{t} \mathrm{ha}^{-1}$ de calcário aplicado no ano, sobre o peso médio e os diâmetros das cabeças de alface. $\mathrm{O}$ efeito residual da calagem verificado principalmente para as maiores doses aplicadas $\left(4 ; 6\right.$ e $\left.8 \mathrm{t} \mathrm{ha}^{-1}\right)$ é concordante com os resultados obtidos por Miranda (1993) e Natale \& Coutinho (1994) em outras culturas.

Hemphill \& Jackson (1982) observaram variações de $10 \%$ até $48 \%$ nas produções de alface, para as mesmas quantidades de calcário aplicadas, conforme o ano agrícola. No presente trabalho, ocorreram variações de $21 \%$ até $54 \%$, indicando o efeito de fatores climáticos influenciando as produções obtidas, independentemente da ação de calagem.

O tratamento MAP (sem cálcio) proporcionou produções de alface seme- lhantes à testemunha nos anos 1 e 3 , e produção significativamente inferior no ano 2 do experimento. Por sua vez, o diâmetro da cabeça de alface neste tratamento foi semelhante à testemunha no ano 1 e apresentou diâmetro significativamente inferior nos anos 2 e 3 do experimento (Tabela 2).

Observou-se que o tratamento sem micronutrientes com aplicação de $4 \mathrm{t} \mathrm{ha}^{-1}$ de calcário proporcionou pesos médios das cabeças de alface nos três anos agrícolas $(92,2 ; 86,8 ; 77,6 \mathrm{~g})$ semelhantes ao tratamento que recebeu $4 \mathrm{t} \mathrm{ha}^{-1}$ de calcário no ano $1 \mathrm{com}$ micronutrientes $(82,2 ; 81,4 ; 96,8 \mathrm{~g})$. O mesmo foi observado para o diâmetro da cabeça de alface quando se comparou o tratamento sem micronutrientes $(18,2 ; 19,0 ; 18,3$ $\mathrm{cm})$ com o tratamento com micronutrientes $(19,4 ; 19,6 ; 16,8 \mathrm{~cm})$.

As produções semelhantes de alface obtidas nos tratamentos contendo ou não micronutrientes podem ser explicadas pela liberação de alguns micronutrientes do corretivo de acidez, conforme relatado por Amaral et al. (1994). Outra hipótese está no fato dos fungicidas Mancozeb e Zineb, utilizados em pulverização, terem fornecido $\mathrm{Mn}$ e $\mathrm{Zn}$ em níveis suficientes para a alface, o mesmo podendo ocorrer quanto a liberação de micronutrientes do esterco de galinha aplicado antes do plantio da cenoura de inverno.
Para o peso médio e diâmetro da cabeça de alface, ocorreu efeito residual do calcário aplicado no ano 1 e no ano 2 do experimento em relação à testemunha sem calagem. Verificou-se efeito residual significativo nos anos 2 e 3 , em relação às doses de 4,6 e $8 \mathrm{t} \mathrm{ha}^{-1}$ de calcário aplicado no ano 1 .

Através da equação de regressão para o primeiro ano entre o peso médio de cabeças e a $\mathrm{V}$ estimou-se que o maior peso médio de cabeças de alface foi de 120,9 g para $80 \%$ de saturação por bases. A relação entre o peso médio da cabeça de alface com a $\mathrm{V}$ em três anos agrícolas está na Figura 1c. Por sua vez, o maior diâmetro da cabeça de alface foi de $20,5 \mathrm{~cm}$, o qual foi estimado a partir da equação de regressão do ano 1 para $72 \%$ de saturação por bases (Figura 1e). As mesmas doses de calcário aplicado nos anos subseqüentes geraram uma relação linear e positiva entre o peso médio e o diâmetro de cabeças e a V.

A relação entre o peso médio da cabeça de alface e o $\mathrm{pH}\left(\mathrm{CaCl}_{2}\right)$ no primeiro ano permite calcular que a cabeça de alface mais pesada seria de 118,2 g para o $\mathrm{pH}\left(\mathrm{CaCl}_{2}\right)$ de 5,6 (Figura 1d). Os maiores diâmetros da cabeça com $22,2 \mathrm{~cm}$ e $24,1 \mathrm{~cm}$ poderiam ser alcançados no $\mathrm{pH}\left(\mathrm{CaCl}_{2}\right)$ de 5,5 e 5,1, respectivamente no primeiro e segundo anos do experimento (Figura 1f). Para os anos 2 e 3, as doses de calcários aplicadas nesse experimento não foram suficientes para explorar na totalidade o potencial genético da alface Brasil 221 quanto ao peso da cabeça, uma vez que a relação direta entre o peso médio de cabeças e o $\mathrm{pH}\left(\mathrm{CaCl}_{2}\right)$ foi linear e positiva (Figura 1d). Relação semelhante foi obtida para o diâmetro da cabeça e o $\mathrm{pH}\left(\mathrm{CaCl}_{2}\right)$ no terceiro ano do experimento (Figura 1f).

Conclui-se que a ação do calcário como corretivo de acidez do solo aplicado no ano e seus efeitos residuais proporcionaram maior produtividade e melhor qualidade comercial da cenoura de inverno e da alface de verão, em três anos agrícolas. As melhores doses de calcário para tais hortaliças são superiores àquelas recomendadas atualmente pelo Instituto Agronômico do Estado de São Paulo (Trani \& Raij,1997). A omissão de B, $\mathrm{Cu}, \mathrm{Mn}$ e $\mathrm{Zn}$ em um dos tratamentos com 


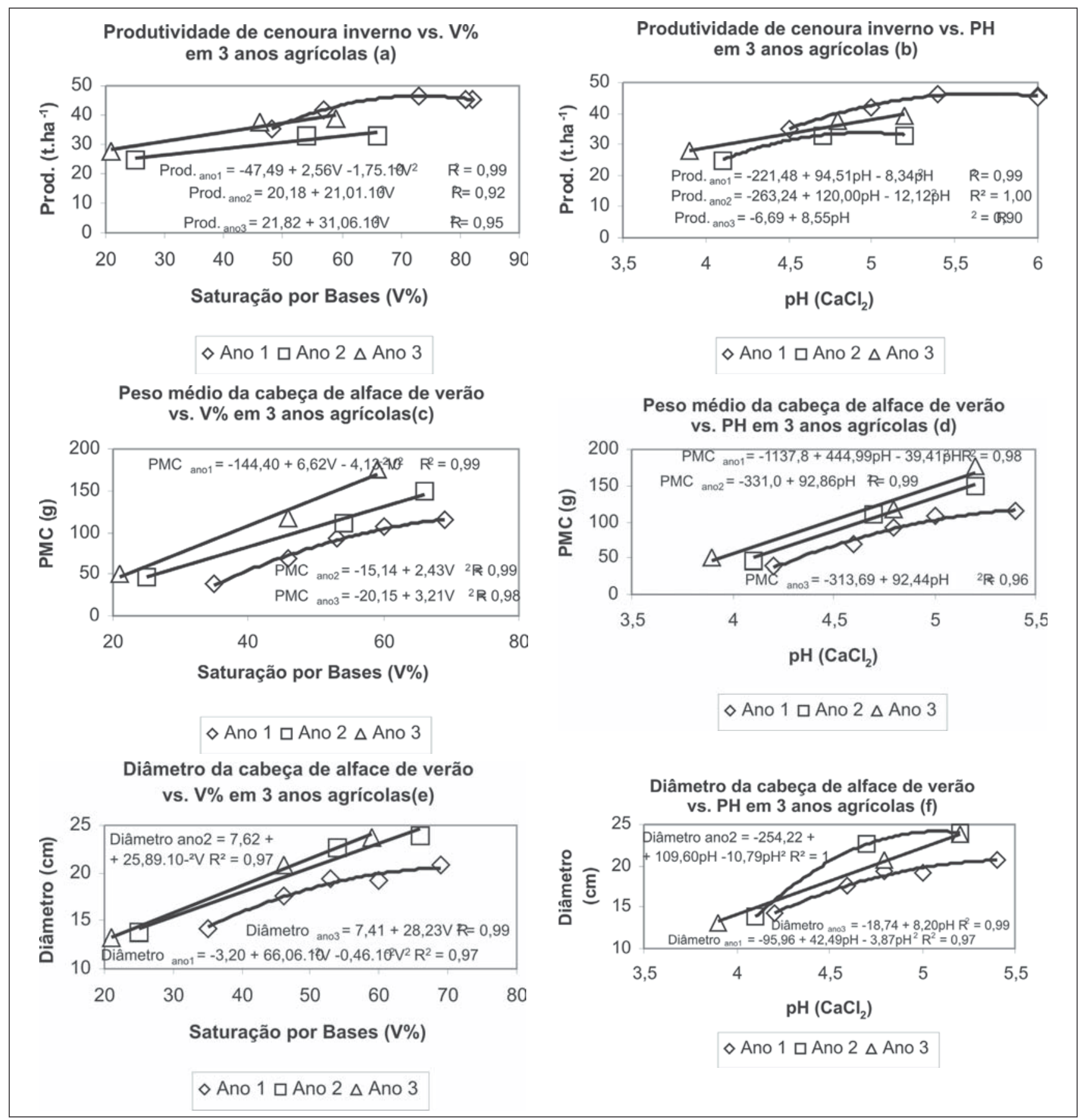

Figura 1. Produtividade de cenoura (a e b), peso médio (c e d) e diâmetro (e e f) da cabeça de alface em função da saturação por bases e $\mathrm{pH}(\mathrm{CaCl})$ do solo para aplicações de calcário em três anos agrícolas do experimento realizado em Monte Alegre do Sul, SP. Campinas, IAC, 1989 a 1992.

calagem acarretou em queda de produtividade e qualidade comercial da cenoura de inverno nos três anos agrícolas, sem afetar, no entanto a produtividade e a qualidade comercial da alface de verão.

\section{AGRADECIMENTOS}

Os autores agradecem ao Sr. Roberto Faria da APTA, Pólo Regional Leste de
Monte Alegre do Sul (SP), pelo apoio na condução dos experimentos em campo e ao Sr. André Luis Trani do Instituto de Química de São Carlos, USP pela revisão e composição final deste trabalho.

\section{LITERATURA CITADA}

AMARAL AS; DEFELIPO BV; COSTA LM; FONTES MPF. 1994. Liberação deZn, Fe, Mne Cl de quatro corretivos de acidez e absorção por alface em dois solos. Pesquisa Agropecuária Brasileira, 29: 1351-1358.
BRASIL, Ministério da Agricultura. Laboratório Nacional de Referência Vegetal (LANARV). 1983. Análise de corretivos, fertilizantes e inoculantes: métodos oficiais. Brasília. 104 p.

CAMARGO LS. 1960. Influência do calcário na produção de cenoura. Bragantia, 19: 35-40.

CAROLUS R. 1975. Calcium relationships in vegetable nutrition and quality. Communications in Soil Science and Plant Analysis, 6: 285-298.

CAMARGO FILHO WP; ALVES HS; CAMARGO AMMP. 2005. Mercado de cenoura no MERCOSUL: análise da produção e de preços no Brasil e na Argentina. Horticultura Brasileira, 23: 2, suplemento CD-ROM. 
GOMES FP; CONAGIN A. 1987. Experimentos de adubação: planejamento e análise estatística. In: SIMPÓSIO DE ESTATÍSTICA APLICADA À EXPERIMENTAÇÃO AGRÍCOLA, 2., 1987, Londrina. Anais... Londrina: Universidade Estadual de Londrina, 102 p.

HEMPHILL JÚNIOR DD; JACKSON TL. 1982.

Effect of soil acidity and nitrogen on yield and elemental concentration of bush bean, carrot and lettuce. Journal of the American Society for Horticultural Science, 107: 740-744.

IFA (INTERNATIONAL FERTILIZER INDUSTRY ASSOCIATION). World fertilizer use manual. Weinheim (Germany), 1992. 627 p.

LAUGHLIN WM; SMITH GR; PETERS MA 1987. Effects of lime and four phosphorus rates on yield of head lettuce, table beets and carrots at Pt. MacKenzie. Agroborealis, 19: 34-38.

LORENZ OA; MAYNARD DN. 1988. Knott's handbook for vegetable growers. 3. ed. New York: John Willey, $456 \mathrm{p}$.

MIRANDA LN. 1993. Resposta da sucessão sojatrigo a doses e modos de aplicação de calcário em solo Glei pouco húmico. Revista Brasileira de Ciência do Solo, 17: 75-82.
NATALE W; COUTINHO ELM. 1994. Avaliação da eficiência agronômica de frações granulométricas de um calcário dolomítico. Revista Brasileira de Ciência do Solo, 18: 55-62.

PATERSON JW. 1979. Liming and fertilizing lettuce profitably. Better Crop with Plant Food, 63: 4-6.

PRADO RM; COUTINHO ELM; ROQUE CG; VILLAR MLP. 2002. Avaliação da escória de siderurgia e de calcários como corretivos da acidez do solo no cultivo da alface. Pesquisa Agropecuária Brasileira, 37: 539-546.

RAIJ B; QUAGGIO JA. 1997. Methods used for diagnosis and correction of soil acidity in Brazil: an overwiew. In. MONIZ AC, ed. Plant soil interactions at low $\mathrm{pH}$ : sustainable agriculture and forestry production. p. 205-215. Brazilian Soil Science Society: Campinas, Viçosa.
TSUNECHIRO A; COELHO PJ; CASER DV; AMARAL AMP; MARTINS VA; BUENO CRF. 2004. Valor da produção agropecuária do estado de São Paulo em 2003. Informações Econômicas, 34: 49-60.

TRANI PE, RAIJ B. 1997. 18. Hortaliças. In: RAIJ B; CANTARELLA H; QUAGGIO J; FURLANI AMC. Recomendações de adubação e calagem para o estado de São Paulo. $2^{\text {a }}$ ed. ver. atual. p. 155-185. Campinas: Instituto Agronômico/ Fundação IAC, (Boletim técnico,100). 